\title{
Mortality from oral and pharyngeal cancer in Brazil: trends and regional patterns, 1979-2002
}

\author{
Antonio Fernando Boing, ${ }^{1}$ Marco Aurélio Peres, ${ }^{1}$ \\ and José Leopoldo Ferreira Antunes ${ }^{2}$
}

Suggested citation Boing AF, Peres MA, Antunes JLF. Mortality from oral and pharyngeal cancer in Brazil: trends and regional patterns, 1979-2002. Rev Panam Salud Publica. 2006;20(1):1-8.

ABSTRACT Objective. To investigate the trends and regional patterns in mortality from oral cancer and pharyngeal cancer in Brazil from 1979 through 2002.

Methods. Data were obtained from the Mortality Information System (Sistema de Informações sobre Mortalidade) database, which is compiled by the Ministry of Health of Brazil. Mortality rates were adjusted by gender and age. The Prais-Winsten generalized linear regression procedure was used to calculate the annual increase or decrease in mortality rates. The time trends for mortality due to oral cancer and to pharyngeal cancer were analyzed by specific anatomical site and by region of the country (North, Northeast, South, Southeast, and Center-West).

Results. In all five regions of Brazil over the period studied, oral cancer mortality remained stable for both genders, but pharyngeal cancer mortality increased for both genders. Mortality from cancer affecting the lips, tongue, gums, mouth floor, palate, other parts of the mouth, and tonsils showed a statistically significant decrease over the period. However, mortality from cancer affecting the oropharynx, hypopharynx, and ill-defined and undefined sites of the oral cavity and the pharynx showed a significant increase. Mortality rates for both oral cancer and pharyngeal cancer were higher in the South and Southeast regions of the country than in Brazil's three other regions.

Conclusions. The relatively larger decrease in mortality from cancer affecting the lips, gums, and other anatomical sites more easily accessible to clinical inspection suggests a possible link between oral and pharyngeal cancer survival and an improved provision of health care services in Brazil in recent decades.

Key words Neoplasms, mouth neoplasms, pharyngeal neoplasms, Brazil.

Oral and pharyngeal cancers are considered to be an important public

\footnotetext{
1 Federal University of Santa Catarina, Department of Public Health, Florianópolis, Santa Catarina, Brazil. Send correspondence to: Antonio Fernando Boing, Universidade Federal de Santa Catarina, Centro de Ciências da Saúde, Departamento de Saúde Pública, Campus Universitário-Trindade, Florianópolis SC—Brasil 88010-970; e-mail: boing@ ccs.ufsc.br

2 University of São Paulo, School of Dentistry, São Paulo, São Paulo, Brazil.
}

health issue in various regions around the world $(1,2)$. In 2002, 485000 new cases of oral cancer, pharyngeal cancer, and nasopharyngeal cancer were diagnosed around the world, and there were 260000 deaths from those cancers in that year (3).

The global distribution of oral cancer and pharyngeal cancer is somewhat heterogeneous. Similarly, mor- tality rates and their trends in recent decades have varied widely among nations (2-4). In Brazil in the 1980s and at the beginning of the 1990s, there was an increase in mortality due to cancer of the oral cavity. The National Institute of Cancer estimated there were approximately 3200 deaths due to oral cancer (groups $\mathrm{C} 00-\mathrm{C} 10$ in the 10th revision of the International Statis- 
tical Classification of Diseases and Related Health Problems (ICD-10)) in 2003, for a rate of 1.83 per 100000 persons $(5,6)$.

Brazil has 26 states and one federal district, and those jurisdictions are officially apportioned into five regions: Southeast, South, North, Northeast, and Center-West. The South and the Southeast have higher incidence and mortality rates from oral cancer and pharyngeal cancer than do the three other regions (7).

In Brazil no studies have investigated mortality trends for the country as a whole for oral cancer and pharyngeal cancer by specific anatomical site, nor are there studies that have looked at historical trends in the mortality rate for pharyngeal cancer.

This study had two major objectives: (1) to analyze the time trends for mortality due to oral cancer and pharyngeal cancer in Brazil by specific anatomical site between 1979 and 2002 and (2) to analyze the patterns in the mortality rates in the five regions of the country.

\section{MATERIALS AND METHODS}

\section{The regions of Brazil}

Of Brazil's five regions, the Southeast is the most industrialized, and it includes two major urban areas, Rio de Janeiro and São Paulo. The CenterWest is the second most urbanized region in Brazil. The Center-West social and economic indicators are generally better than those of the North and Northeast, and below those of the South and Southeast. The Northeast is the poorest region economically, and it has the highest infant mortality and illiteracy rates. The North is the largest region in terms of territory, and it has the second worst social and health indicators. The South has the best social indicators, the longest life expectancy (70.8 years in 1999), and the lowest level of illiteracy (8).

\section{Data sources}

In Brazil the classification of underlying causes of death used the 9th re-

TABLE 1. Anatomical sites studied in the investigation of oral and pharyngeal cancer in Brazil, 1979-2002, and the sites' codes in the 10th revision of the International Statistical Classification of Diseases and Related Health Problems (ICD-10)) and the 9th revision of the International Classification of Diseases (ICD-9) ${ }^{\mathrm{a}}$

\begin{tabular}{lll}
\hline \multicolumn{1}{c}{ Site } & \multicolumn{1}{c}{ ICD-10 } & ICD-9 \\
\hline Lips & C00 & 140 \\
Tongue & C01-C02 & 141 \\
Gums & C03 & 143 \\
Mouth floor & C04 & 144 \\
Major salivary glands & C07-C08 & 142 \\
Palate & C05 & $145.2-145.5$ \\
Other parts of the mouth & C06.0-C06.2 & $145.0 ; 145.1 ; 145.6$ \\
Tonsils & C09 & $146.0-146.2$ \\
Oropharynx & C10 & $146.3-146.9$ \\
Nasopharynx & C11 & 147 \\
Piriform sinus & C12 & 148.1 \\
Hypopharynx & C13 & $148.0 ; 148.2-148.9$ \\
Malignant neoplasia of other sites; & C14; C06.8; C06.9 & $149 ; 145.8 ; 145.9$ \\
$\quad$ ill-defined and unspecified sites of lips, & & \\
oral cavity, and pharynx & & \\
a ICD-9 was used in Brazil to classify the underlying cause of death from 1979 to 1995; ICD-10 was used beginning in 1996. &
\end{tabular}

vision of the International Classification of Diseases (ICD-9) from 1979 to 1995; beginning in 1996, ICD-10 was used. The data assessed in this article include deaths resulting from oral cancer (ICD-9 codes 140.0-145.9; ICD-10 codes C00.0-C8.9) and from pharyngeal cancer (ICD-9 codes 146.0-149.9; ICD-10 codes C09-C14.8) between 1979 and 2002. Table 1 shows the correspondence of the codes used in the two ICD revisions for the assessment of oral cancer and pharyngeal cancer, according to the subsite of origin of the tumor (9).

The data on oral cancer and on pharyngeal cancer were obtained from the Mortality Information System (Sistema de Informações sobre Mortalidade) database, which is compiled by the Ministry of Health of Brazil (10). The number of inhabitants per region by gender and age was obtained from the Web site of the Health Information Department of the Brazilian Ministry of Health (Departamento de Informação e Informática do Sistema Único de Saúde, or DATASUS) (11). These statistics are derived from the censuses conducted in Brazil in 1980, 1991, and 2000, and from a population count conducted in 1996 . (It was discovered that the census con- ducted in 1991 had had methodological problems. Therefore, the Government decided to carry out a new population count, which differed from the traditional census in that information related to economic production, housing, and other socioeconomic variables was not collected.)

\section{Statistical analysis}

For the country as a whole, we investigated mortality trends for each anatomical site (Table 1). We also analyzed variations in mortality between males and females and among the different regions of the country, as specified above. Deaths were classified into two categories, oral and pharyngeal, in order to ensure a sufficient number of cases per region and consequent greater data stability. Deaths were also classified and analyzed in order to test the hypothesis of the existence of two distinct mortality trend patterns for oral cancer and pharyngeal cancer in Brazil, with one pattern in the South and the Southeast and another in the North, Northeast, and Center-West.

The mortality rates (the number of deaths from oral and pharyngeal can- 
cer per 100000 inhabitants) were standardized by gender and age (every 5 years up to age 75 years and older) through the direct method, using as a standard the Brazilian male population in the year 2002 (11). This was done in order to avoid any interference in the analysis resulting from recent changes in the age profile of the Brazilian population, and in the regions specifically.

Trend estimation followed methodological indications presented by Antunes et al. (12). The Prais-Winsten generalized linear regression procedure was used to calculate the annual increase or decrease in mortality rates, thus allowing for the correction of firstdegree autocorrelation in the timeseries analysis. This procedure allowed us to classify mortality rates as increasing, decreasing, or stable, as well as to quantify the mean annual increase or decrease in the measure, and its respective $95 \%$ confidence interval (CI). The mortality rates were considered as increasing when the regression coefficient was positive, and as decreasing when the coefficient was negative. Rates were considered as stable when the regression coefficient was not significantly different from zero $(P>0.05)$. Statistical analysis was carried out using SPSS software version 8.0 (SPSS Inc., Chicago, Illinois, United States).

The visual presentation of time series trends in graphical form is often hampered by the roughness of the resulting frequency polygon. This is caused by random variation, which, in addition to the trend, appears in the time series. In order to prevent this effect from hindering the visual assessment of trends, the graphs presented in this article are smoothed using a thirdorder moving average process (13).

\section{RESULTS}

Between 1979 and 2002, there were 38263 deaths from oral cancer and 40314 deaths from pharyngeal cancer in Brazil. This corresponds, respectively, to $1.80 \%$ and $1.89 \%$ of total deaths due to neoplasia in this period. The ratio between the male and female
FIGURE 1. Distribution of deaths from oral cancer (38 263 deaths) and pharyngeal cancer (40 314 deaths), according to anatomical site, Brazil, 1979-2002

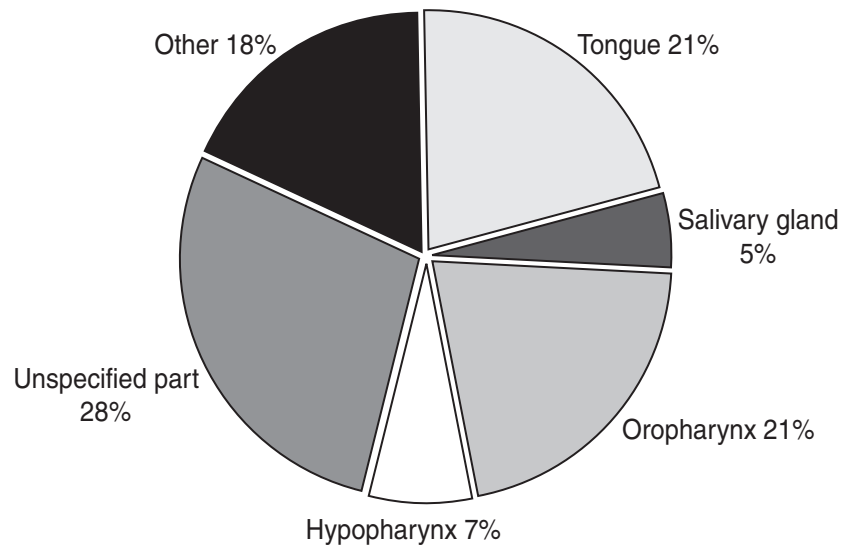

mortality rates was 4:1 for oral cancer and 6:1 for pharyngeal cancer.

Figure 1 shows the proportional distribution, by anatomical site, of the deaths from oral cancer and pharyngeal cancer. Ill-defined or unspecified locations accounted for more than onequarter of the deaths $(27.61 \%)$, followed by the tongue $(21.27 \%)$ and the oropharynx (20.79\%).

When all sites were classified into two groups, mouth and pharynx, we found a stable pattern in the mortality rates for oral cancer for both genders ( $P=0.38$ for males and $P=0.45$ for females for the regression coefficient being significantly different from zero). In contrast, the rate of mortality from pharyngeal cancer for males rose from 1.78 per 100000 in 1979 to 2.70 per 100000 in 2002, representing a mean annual increase of $2.02 \%(P<$ 0.01). For females, the rates per 100000 went from 0.27 in 1979 to 0.42 in 2002, a mean annual increase of $1.95 \%(P<$ 0.01) (Figure 2).

Throughout the period studied, the South and Southeast regions showed the highest mortality rates for both oral cancer and pharyngeal cancer (Figure 3). There was an upward trend in the mortality rate for oral cancer in the South, with a mean increase of $0.29 \%$ annually (95\% CI, $0.07 \%-$ $0.51 \%$ ), and in the Northeast, of $1.42 \%$ annually (95\% CI, 0.37\%-2.48\%). Mortality from oral cancer in the three other regions remained stable. Pharyngeal cancer increased at a mean annual rate of $3.69 \%$ (95\% CI, $2.84 \%-4.55 \%$ ) in the Center-West region.

When the five regions were divided into two groups, the southern area (the South and Southeast regions) and the northern area (the North, Northeast, and Center-West regions), we found a stability in oral cancer among females. There was a mean annual increase of $1.2 \%(P=0.02)$ for males in the northern area. For pharyngeal cancer in both areas, the mortality rates rose $(P<$ 0.02 ). However, while the mean annual increase in the southern area was $1.40 \%$ (95\% CI, $0.99 \%-1.80 \%$ ), in the northern area it was $4.10 \%(95 \% \mathrm{CI}$, $3.55 \%-4.67 \%$ ).

Table 2 shows the total number of deaths, the mean mortality rate, and the mortality trend for each specific anatomical site. Most of the anatomical sites had statistically significant reductions during the period, with the largest declines being with the lips and the gums. In contrast, the oropharynx, hypopharynx, and ill-defined and unspecified sites of the oral cavity and pharynx showed increasing mortality rates between 1979 and 2002. The other sites showed stable trends over the period. 
FIGURE 2. Time-series mortality for oral cancer (A) and pharyngeal cancer (B), according to gender, Brazil, 1979-2002
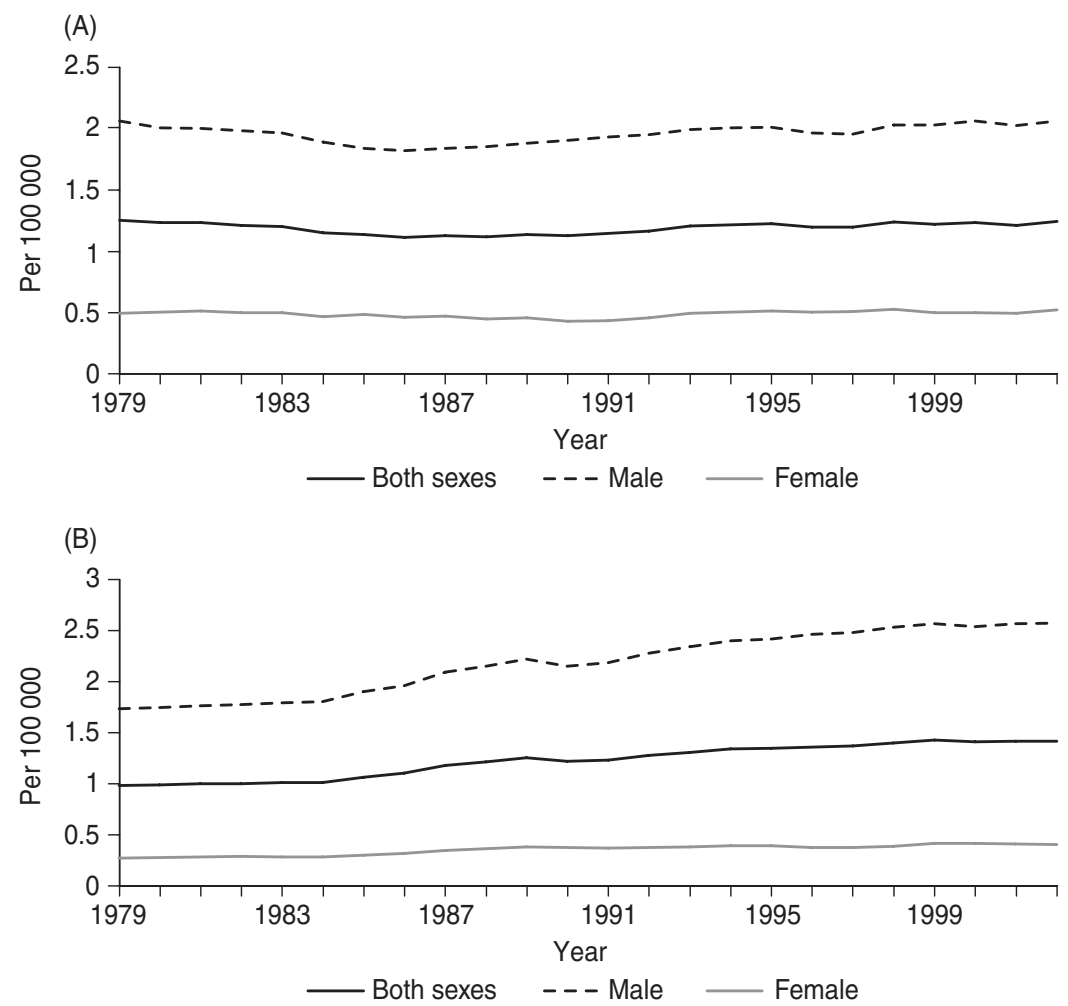

a Standardized by gender and age group, based on the Brazilian male population of 2000 , and smoothed by third-order moving average.

\section{DISCUSSION}

Oral cancer mortality in Brazil was stable over the study period, whereas the pharyngeal cancer death rate increased. There were also different patterns of mortality in the various regions of the country. However, trends and spatial patterns in oral and pharyngeal cancer mortality should be discussed in terms of differential levels of exposure to alcohol and tobacco, as well as disparities in access to health services. The epidemiological appraisal should also consider potential differences in the quality of the reporting of deaths.

Wünsch-Filho (5) also reported stability in oral cancer mortality and a rise in the mortality rates for pharyngeal cancer in Brazil during the 1980s and the early 1990s. A study of the trends and spatial distribution of oral cancer in the city of São Paulo by An- tunes et al. (14) reported stable mortality rates for oral cancer between 1980 and 1998. However, analysis by specific anatomical site found a decrease in gum cancer and lip cancer, and an increase of cancer in the unspecified parts of the mouth. In our study we found the same trends for all of these sites. Wünsch-Filho (7) has predicted that oral cancer and pharyngeal cancer will become an increasing problem in Brazil in the coming decades. However, according to our findings, death rates from oral cancer were stable when the analyzed sites were all considered together. When the sites were investigated separately, only tumors of the salivary glands and in illdefined and unspecified sites did not show statistically significant declines between 1979 and 2002. The same does not apply to pharyngeal cancer, where no sites with decreasing rates have been identified.
While the Ministry of Health's Mortality Information System stands out for its wide coverage, it still has some limitations that must be considered when interpreting these mortality data (15). These limitations are due to the inadequate completion of the death certificate, including errors in the indication of the underlying cause of death, and the underreporting of deaths, especially in places where effective medical care is poorly available. The quality of death certificates should also be mentioned as one of the factors that possibly distort the apparent mortality trends for oral cancer and pharyngeal cancer. Deaths registered as due to neoplasms of unspecified nature (code 239.9 in ICD-9, and code C80 in ICD-10) can be associated with the underreporting of oral and pharyngeal cancer cases. Several Brazilian municipalities, mainly in deprived areas in the North and the 
FIGURE 3. Time-series mortality for oral cancer (A) and for pharyngeal cancer (B), in the five regions of Brazil, 1979-2002a
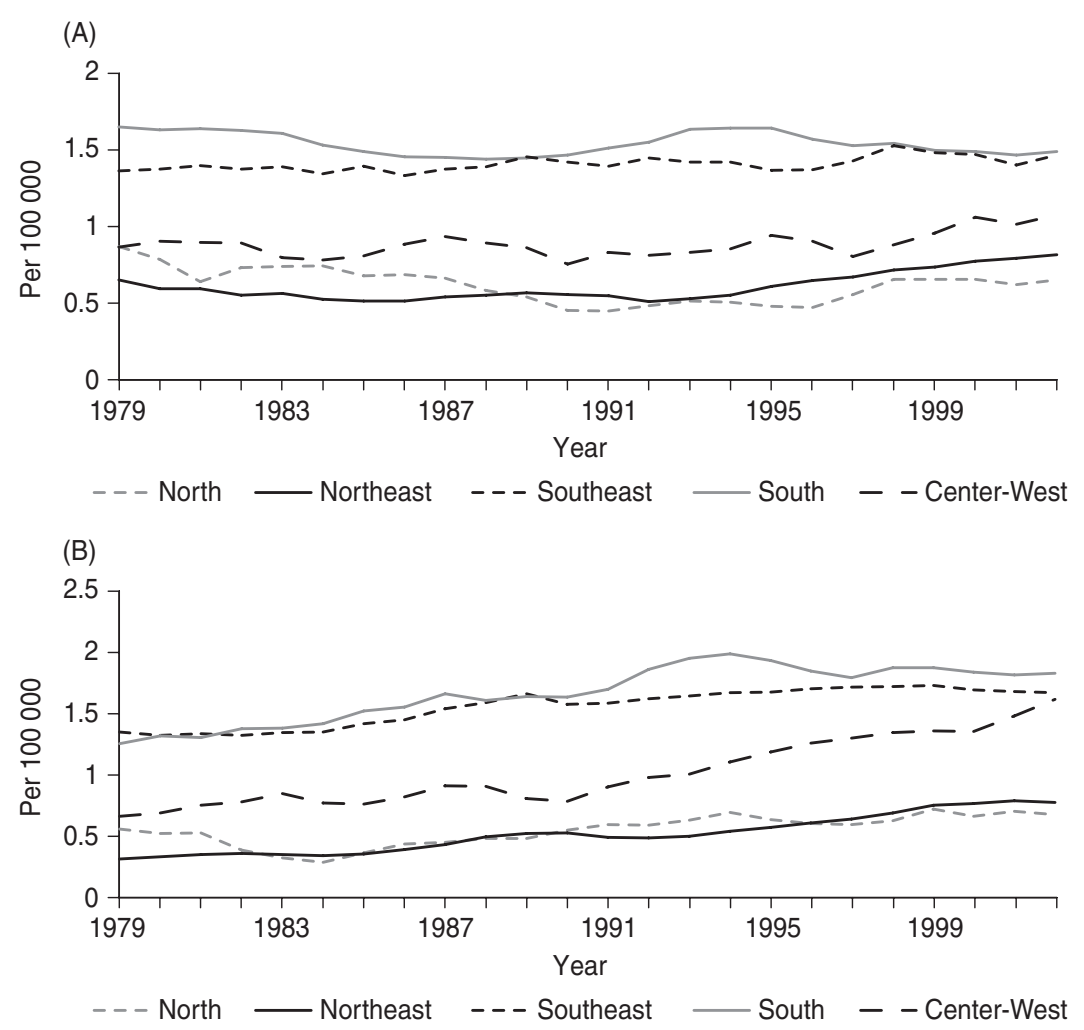

a Standardized by gender and age group, based on the Brazilian male population of 2000 , and smoothed by third-order moving average.

Northeast, lack adequate information on cause-specific mortality and have a high proportion of unspecified deaths (16). Nevertheless, in Brazil overall, the percentage of deaths classified in the category of ill-defined causes has fallen systematically since the 1980s. Various deficiencies and different levels of quality still affect the system of death registration in Brazil. Some of these factors may partially explain the differences in mortality patterns among the regions of Brazil.

When analyzing the incidence of and mortality due to oral cancer in Brazil the highest rates of mortality from pharyngeal cancer were found in the South and Southeast. However, when the regions were grouped into sets, the set including the North, Northeast, and Center-West regions showed an increase in the rates of pharyngeal cancer three times greater than that found in the South and Southeast regions.
Many studies indicate a link between mortality trends and variations in the consumption of alcohol and tobacco $(4,17)$. Carlini-Marlatt (18) reported that there was a $74 \%$ increase in the per capita consumption of alcoholic beverages in Brazil between 1970 and the mid-1990s. The author also reported a 39\% increase in the per capita cigarette consumption in the same period. In Brazil a decline in tobacco consumption only began in the 1990s. The effects of this decrease may not be seen in morbidity and mortality patterns until future decades. Further, there is ongoing concern that, in spite of the lower rates of cigarette consumption overall, smoking among younger persons may have increased (19). The Brazilian phase of the World Health Survey found a $22.5 \%$ prevalence of smoking among males and of $14.4 \%$ among females in 2003 (20). For alcohol consumption the prevalence was
$25.0 \%$ for males and $6.0 \%$ for females. Regional differences in alcohol and tobacco consumption patterns have also been reported. The proportion of people aged between 12 and 65 years old identified as current consumers of alcohol and of tobacco is greater in the Southeast $(71.0 \%$ and $43.6 \%$, respectively) and the South $(69.4 \%$ and $44.1 \%$, respectively) than in the Northeast $(68.0 \%$ and $37.4 \%$, respectively), Center-West $(60.5 \%$ and $34.0 \%$, respectively), and North $(53.0 \%$ and $33.8 \%$, respectively) (21).

The unfavorable epidemiologic situation with oral cancer and pharyngeal cancer in Brazil could be improved if governmental actions were taken to reduce alcohol and tobacco consumption. These initiatives could range from reducing financial support for the tobacco agribusiness and for the production of alcoholic beverages to increasing prices for cigarettes and al- 
TABLE 2. Number and relative proportion (\%) of deaths from oral and pharyngeal cancer according to anatomical site, with mean mortality rate and annual mortality trend, Brazil, 1979-2002

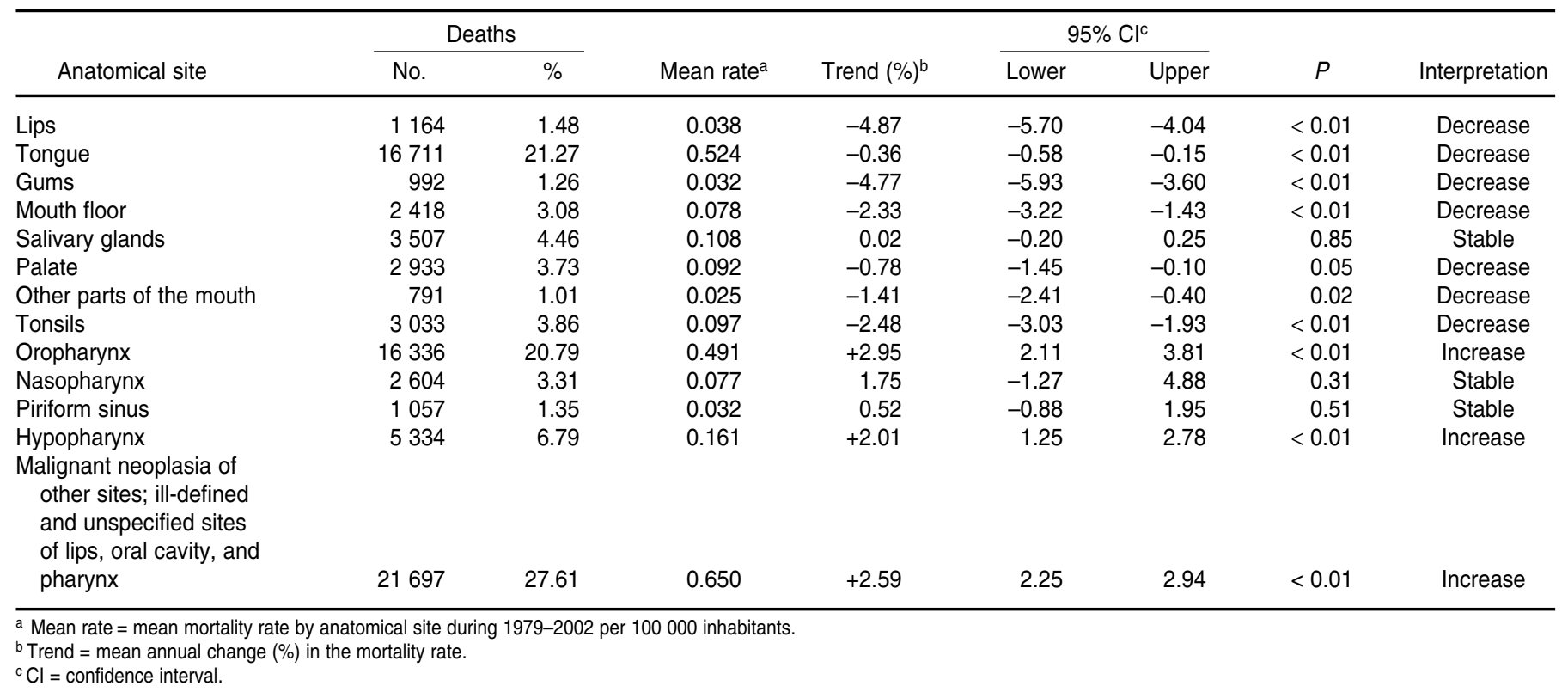

coholic beverages, which rank among the lowest worldwide. These initiatives should also include restrictions on the advertising of these products and on the places where tobacco can be consumed and where alcoholic beverages can be sold. Any such measures are expected to face strong opposition from the alcohol and tobacco industries, given that Brazil has a large sugar cane (and alcohol) sector, and it is one of the world's largest producers of tobacco (19).

Aside from the registration system and the etiological factors, another possible influence on the mortality rates from oral cancer and pharyngeal cancer are the health services that are available in Brazil. In our study, the lips and the gums were the anatomical sites with the largest reductions in mortality rates. These sites are also the ones that can be viewed most easily and thus offer the easiest identification of lesions at the time of a clinical exam. Among cancers of sites within the oral cavity, only cancer of the salivary glands and cancers of ill-defined sites did not show decreasing rates. In contrast, the pharyngeal cancer sites, which are more difficult to view, showed stable or increasing rates, with the excep- tion of tumors of the tonsil, a region of easier access. Analyzing data from the city of São Paulo, Antunes et al. (14) also found a possible positive relationship between the decline in lip cancer and gum cancer and the increased supply of health care services.

When Matos et al. (22) studied the access that Brazilians over age 60 have to health care services, those researchers found a significant relationship between place of residence (the five regions of Brazil) and visits to the dentist. Using the South region as the reference, the odds ratio for never having had a dentist appointment was 2.32 (95\% CI, 1.62-3.34) for residents of the Northeast region and $2.42(95 \% \mathrm{CI}$, 1.68-3.48) for residents of the North region. This finding shows the evident deep regional inequalities affecting the access to diagnosis and treatment in Brazil.

Carvalho et al. (23) studied the influence of access to health care services on the survival of patients with oral cancer and oropharyngeal cancer in a Brazilian hospital between 1953 and 1997. After controlling for covariates, survival was found to increase throughout the study period $(P<$ $0.001)$, reflecting the more widespread provision of treatment based on the combination of surgery and radiotherapy. In addition, over the period studied, there was an increase in the proportion of tumors diagnosed in the early stages of development.

Allison et al. (24) followed a group of 188 patients in Canada with head and neck cancer, and they highlighted the importance of primary health care in the early diagnosis of tumors affecting the upper aerodigestive tract. The authors also reported there was a doseresponse relationship between a delayed diagnosis and the odds of the disease having developed to an advanced stage.

The American Cancer Society (25) has pointed out the importance of access to health services in the prevention of oral cancer. That organization has also recommended an annual examination of the mouth and oropharynx for asymptomatic men and women aged more than 40 years, especially for smokers. However, meeting this need would require improvements in the health care system of the United States, where only $15 \%$ of adults 40 years of age and older have had an oral cancer examination done during their lifetime (26). Many other studies have indicated that dental 
professionals could contribute to the prevention and early diagnosis of oral cancer and pharyngeal cancer $(27,28)$.

During the period covered by our research, the Brazilian health care sector underwent extensive changes, with an expansion in health care and dental coverage by the public sector that greatly increased the proportion of the population able to receive quality health care. Changes also took place in the private sector, through private health care plans and an increase in the number of health care professionals.

Over the period analyzed in this study, ill-defined and unspecified sites in the mouth and pharynx accounted for a higher proportion of deaths and also showed an upward trend in the mortality rate. These patterns indicate that the number of cases diagnosed at an advanced stage is high, and that inaccurate entry of information on the death certificate is common. Diagnosis must occur during the initial stages of the disease in order to provide the patient a better prognosis, fewer functional problems and social consequences (such as peer rejection and a decrease in self-esteem), and a better quality of life. Earlier diagnosis also lowers the cost of treatment.
Further studies testing the hypothesis of an association between the supply of health services and lower mortality rates for oral cancer and pharyngeal cancer in Brazil are needed. Such studies could clarify the important association suggested in this study and other studies, but which has yet to be confirmed.

Acknowledgements. Antonio Fernando Boing was partially supported by a grant from the Coordenação de Aperfeiçoamento de Pessoal de Nível Superior (CAPES).

\section{REFERENCES}

1. Macfarlane GJ, Boyle P, Evstifeeva TV, Robertson C, Scully C. Rising trends of oral cancer mortality among males worldwide: the return of an old public health problem. Cancer Causes Control. 1994;5:259-65.

2. Franceschi S, Bidoli E, Herrero R, Muñoz N. Comparison of cancers of the oral cavity and pharynx worldwide: etiological clues. Oral Oncol. 2000;36:106-15.

3. International Agency for Research on Cancer. GLOBOCAN 2002. Cancer incidence, mortality and prevalence worldwide. Available from: http:/ / www-depdb.iarc.fr/globocan/ globoframe.htm [Internet site]. Accessed 29 September 2004.

4. La Vecchia C, Lucchini F, Negri E, Levi F. Trends in oral cancer mortality in Europe. Oral Oncol. 2004;40:433-9.

5. Wünsch-Filho V, Moncau JE. Mortalidade por câncer no Brasil 1980-1995: padrões regionais e tendências temporais. Rev Assoc Med Bras. 2002;48:250-7.

6. Brasil, Ministério da Saúde, Instituto Nacional de Câncer. Estimativas da incidência e mortalidade por câncer no Brasil 2003. Rio de Janeiro: Kartepier do Rocha; 2003.

7. Wünsch-Filho V. The epidemiology of oral and pharynx cancer in Brazil. Oral Oncol. 2002;35:737-46.

8. Organização Pan-Americana da Saúde. Indicadores básicos para a saúde no Brasil: conceitos e aplicações. Brasília: OPAS; 2002.

9. Fritz A, Percy C, Jack A, Shanmugaratnam K, Sobin L, Parkin DM, et al., eds. International classification of diseases for oncology (ICD-O). Third ed. Geneva: World Health Organization; 2000.

10. Brasil, Ministério da Saúde. Sistema de informações sobre mortalidade. Available from: http://www.datasus.gov.br [Internet site]. Accessed 10 July 2004.
11. Brasil, Ministério da Saúde. Departamento de Informação e Informática do Sistema Único de Saúde. Available from: http://tabnet. datasus.gov.br/cgi/ibge/popmap.htm [Internet site]. Accessed 25 July 2004.

12. Antunes JLF, Waldman EA. Trends and spatial distribution of deaths of children aged 1260 months in São Paulo, Brazil, 1980-98. Bull World Health Organ. 2002;80:391-8.

13. Gaynor PE, Kirkpatrick RC. Introduction to time-series modeling and forecasting in business and economics. New York: McGrawHill; 1994.

14. Antunes JLF, Biazevic MGH, de Araújo ME, Tomita NE, Chinellato LEM, Narvai PC. Trends and spatial distribution of oral cancer mortality in São Paulo, Brazil, 1980-1998. Oral Oncol. 2001;37:345-50.

15. Carvalho DM. Grandes sistemas nacionais de informação em saúde: revisão e discussão da situação atual. Inf Epidemiol SUS. 1997;4: $8-46$.

16. Mello Jorge MHP, Gotlieb SLD. As condições de saúde no Brasil. Rio de Janeiro: Fiocruz; 2000.

17. La Vecchia C, Levi F, Lucchini F, Negri E, Boyle P. Trends in cancer mortality in the USSR, 1965-1990. Int J Cancer. 1994;56:31-9.

18. Carlini-Marlatt B. A população é jovem e o país é quente: estimativas de consumo de álcool e tabaco no Brasil pelos dados das indústrias produtoras. J Bras Depend Quim. 2001;2: 3-8.

19. Brasil, Instituto Nacional do Câncer. Por um mundo sem tabaco: mobilização da sociedade civil. Rio de Janeiro: INCA; 2004

20. Szwarcwald CL, Viacava F, Vasconcellos MTL, Leal MC, Azevedo LO, Queiroz RSB, et al. O Brasil em números. Radis. 2004,23:14-33.

21. Carlini EA, Galduróz JCF, Noto AR, Nappo AS. I Levantamento Domiciliar sobre o Uso de
Drogas Psicotrópicas no Brasil: estudo envolvendo as 107 maiores cidades do país-2001. São Paulo: Cromosete; 2002.

22. Matos DL, Giatti L, Lima-Costa MF. Fatores sócio-demográficos associados ao uso de serviços odontológicos entre idosos brasileiros: um estudo baseado na Pesquisa Nacional por Amostra de Domicílios. Cad Saude Publica. 2004;20(5):1290-7.

23. Carvalho AL, Ikeda MK, Magrin J, Kowalski LP. Trends of oral and oropharyngeal cancer survival over five decades in 3267 patients treated in a single institution. Oral Oncol. 2004;40:71-6.

24. Allison P, Locker D, Feine JS. The role of professional diagnostic delays in the prognosis of upper aerodigestive tract carcinoma. Oral Oncol. 1998;34:147-53.

25. Smith RA, Mettlin CJ, Davis KJ, Eyre $\mathrm{H}$. American Cancer Society guidelines for the early detection of cancer. CA Cancer J Clin. 2000;50:34-49.

26. Horowitz AM, Nourjah PA. Factors associated with having oral cancer examinations among US adults 40 years of age or older. J Public Health Dent. 1996;56(6):331-5.

27. Winn DM, Sandberg AL, Horowitz AM, Diehl SR, Gutkind S, Kleinman DV. Reducing the burden of oral and pharyngeal cancers. J Calif Dent Assoc. 1998;26(6):445-51.

28. Macpherson LMD, McCann MF, Gibson J, Binnie VI, Stephen KW. The role of primary healthcare professionals in oral cancer prevention and detection. Br Dent J. 2003;195(5): 277-81.

Manuscript received 18 July 2005. Revised manuscript accepted for publication 3 January 2006. 
RESUMEN Objetivo. Investigar las tendencias y patrones regionales mostrados por la mortalidad por cáncer bucal y faríngeo en el Brasil de 1979 a 2002.

Métodos. La información se obtuvo de la base de datos del Sistema de Informações

La mortalidad por cáncer bucal y faríngeo en el Brasil: tendencias epidemiológicas regionales, 1979-2002

Palabras clave sobre Mortalidade, recopilada por el Ministerio de Salud del Brasil. Las tasas de mortalidad se ajustaron según el sexo y la edad y se aplicó el método de regresión lineal generalizada de Prais-Winsten para calcular el aumento o la reducción anual en las tasas de mortalidad. Las tendencias temporales de la mortalidad por cáncer bucal y cáncer faríngeo se analizaron por sitio anatómico y región del país (norte, noreste, sur, sureste y centrooccidental).

Resultados. Durante el período estudiado, en todas las cinco regiones del Brasil la mortalidad por cáncer bucal se mantuvo estable en ambos sexos, pero la mortalidad por cáncer faríngeo aumentó en los dos. La mortalidad ocasionada por cánceres en los labios, la lengua, las encías, el piso de la boca, el paladar, otras partes de la cavidad bucal y las amígdalas mostró un descenso estadísticamente significativo durante el período examinado. En cambio, la mortalidad por cánceres en la orofaringe, la hipofaringe y puntos mal definidos o indefinidos de la cavidad bucal y la faringe mostró un aumento significativo. Las tasas de mortalidad por cáncer bucal y por cáncer faríngeo fueron más altas en las regiones sur y sureste que en las otras tres regiones del Brasil.

Conclusiones. La reducción más grande que se produjo, en términos relativos, en la mortalidad por cánceres de los labios, encías y otros sitios anatómicos más accesibles a la inspección clínica apunta a un posible vínculo entre la supervivencia de pacientes con cáncer bucal y faríngeo y una mejor provisión de asistencia sanitaria en el Brasil en décadas recientes.

Neoplasias, neoplasias de la boca, neoplasias faríngeas, Brasil.

\section{ERRATA \\ Rosenfeld $S$ et al. Medication as a risk factor for falls in older women in Brazil. (Rev Panam Salud Publica 2003;13(6):369-375).}

Two errors appear in Table 2 of the published version (p.372). The 95\% confidence interval $(95 \% \mathrm{Cl})$ of the adjusted odds ratio $(\mathrm{OR})$ for the association between single falls and the use of beta blockers in persons having a body mass index $\leq 30$ should be $0.18-01.41$, rather than $0.18-0.41$. Similarly, the $95 \% \mathrm{Cl}$ of the adjusted OR for the association between single falls and the use of diuretics in persons without musculoskeletal disease should be $0.18-01.37$, rather than $0.18-0.37$. 